\title{
Reverse retirement - a mixed methods study of returning to work in England, Italy and the United States: propensities, predictors and preferences
}

\author{
By Deborah Smeaton ${ }^{1}$, Mirko Di Rosa ${ }^{2}$, Andrea Principi ${ }^{2} \mathcal{E}$ \\ ZOE BUTLER ${ }^{3}$
}

\begin{abstract}
Using methodological triangulation the study examines reverse retirement in Italy, the United States and England to explore the salience of cultural and structural factors and to consider the extent to which returning to work is a constrained choice. Analysis of harmonised panel data (HRS, ELSA and SHARE) indicates that reverse retirement is most common in the United States and extremely rare in Italy. In the liberal economies of the United States and England, financial factors are key determinants, including retirement income, having more children, children under 30 and mortgage debt. However, a certain degree of advantage is a prerequisite for returning to work, including higher education, good health, younger age, and free from caring responsibilities - opportunity structures and

\footnotetext{
${ }^{1}$ Deborah Smeaton, Policy Studies Institute, Faculty of Social Sciences and Humanities, University of Westminster, London UK

${ }^{2}$ Mirko Di Rosa E Andrea Principi, National Institute of Health and Science on Aging (INRCA), Ancona, Italy

${ }^{3}$ Zoe Butler, School of Physiology, Pharmacology and Neuroscience, University of Bristol, Bristol, UK
} 
International Journal of Ageing and Later Life

capacity to work therefore remain barriers for some older groups. Despite international convergence in the policy landscape, "retirement" continues to hold different meanings in the three distinct national contexts with implications for later life working.

Keywords: unretirement, reverse retirement, later life working, active ageing.

\section{Introduction}

Developed economies are facing a range of interlinked challenges associated with population ageing, declining male labour force participation and deteriorating support ratios (Hofäcker 2010; ONS 2016). These population developments have led to widespread skills shortages (CIPD 2012; UKCES 2014) and a feared pension crisis (DWP 2014a; Giarini 2009). In response to concerns that current systems will be unable to cope, governments have targeted key areas for reform, including social and health care, education, benefits and pensions. Employment among older workers is also high on the international policy agenda, with a range of policy incentives and deterrents implemented to prevent premature labour market exit before state pension age (SPa) (OECD 2015; WHO 2002). Working beyond SPa is also being encouraged as part of an "active ageing" agenda (European Commission 2014; Foster \& Walker 2015; WHO 2002). The goals of "active" or "productive" ageing have been widely adopted across the Western industrialised world as a solution to the "problem" of population ageing, as exemplified in the following excerpt from a 2011 European Commission policy document: "We need to enable older people to make their contribution to society, to rely more on themselves and to depend less on others... Active ageing seeks to help older people to remain longer in the labour market" (EC 2011: 14).

There is a considerable body of evidence which highlights the complexity of retirement decision-making, but the range of policy levers and incentives which influence retirement trends are well understood and considerable international progress has been made in raising employment participation among the 50+ (DWP 2014b; Hasselhorn \& Apt 2015). Less widely investigated is employment beyond $\mathrm{SPa}$ and studies which have addressed this age group have typically conflated individuals who 
have continued working up to and beyond SPa with the same employer, that is, "continuers" with individuals who have retired, and then chosen to return to work, that is, reverse retirees ${ }^{1}$ (Eurofound 2012; Klevmarken 2010; Larsen \& Pedersen 2013; Parry \& Taylor 2007; Reynolds et al. 2012; Smeaton \& McKay 2003). The characteristics, motivations and employment determinants of these two groups are likely to differ.

Very few studies have focussed exclusively on reverse retirees (also referred to in the literature as "unretirement" - these terms are used interchangeably throughout this article), and given the scarcity of research there is a need to better understand the phenomenon. Insights are particularly important at this point in time given international moves to steadily increase SPa towards the age of 70 for men and women and the fact that increased participation rates over the past 10 years have primarily been a retention phenomenon with older workers remaining in their jobs for longer (Smeaton 2015). Understanding reverse retirement can help in the design of policies and incentives that might aid those seeking such a transition. Some individuals may have been forced out of the labour market due to redundancy, or may have experienced enforced retirement for health or caring reasons. Others may have voluntarily exited the labour market but found retirement did not live up to expectations. As circumstances change, opportunities to return to the workplace may be welcomed and measures to improve recruitment rates later in life are therefore warranted. There are concerns, however, that while the "active ageing" agenda promotes longer working lives on the grounds of health and well-being benefits (European Commission 2014; WHO 2002), withholding access to state pensions until age 68 or above may lead to hardship later in life as some groups of older people find themselves unable, despite economic need, to continue working (Macnicol 2010). Significant demand-side obstacles can also hinder unretirement; evidence suggests that while employers are now more willing to retain older workers and will take steps to maintain their employment, the impetus to recruit older workers has not increased to the same extent (Kidd et al. 2012); a number of studies emphasise the continued significance of age discrimination in the labour market (Porcellato et al. 2010; Smeaton \& Vegeris 2009; TAEN

\footnotetext{
${ }^{1}$ It should be noted that many individuals who self-report as "retired" are below state pension age.
} 
International Journal of Ageing and Later Life

2013). Moreover, while the right to work as long as desired is valued, this freedom to choose is a hollow right insofar as financial necessity is a key determinant.

The few studies that have investigated reverse retirement, most of which are American in focus, have presented the transition conceptually as either (1) planned in advance and seen as part of an expected retirement lifestyle or (2) in response to a "shock" in retirement such as an unwelcome narrowing of social engagement, retirement not living up to expectations or inadequacy of finances (Cahill et al. 2010; Haider \& Loughran 2001; Kanabar 2012; Kutlu-Koc 2014; Lahey et al. 2006; Maestas 2010; Petterson 2011). These studies consistently find a higher incidence of reverse retirement associated with being male, of younger age and in good health. Evidence relating to economic factors however is more mixed. Maestas (2010) finds that the probability of unretirement in America is unresponsive to declines in net worth or increases in medical expenses after retirement and that unretirement is largely a planned and anticipated event. Petterson (2010) observes, in the Swedish context, low financial incentives to re-enter the labour force post-retirement due to comparably generous social insurances, providing secure pension incomes; reverse retirement in Sweden is therefore driven by lower satisfaction with retirement and it is the higher educated and those on higher pension incomes who are most likely to reverse retire. Haider and Loughran (2001: 20) observe that it is the better educated and wealthier Americans who are most likely to work at older ages, going so far as to conclude that "work may be closer to leisure for the majority of elderly workers." Similarly, in a study of English male retirees by Kanabar (2015), pension wealth was not found to have an effect on the hazard of unretirement, suggesting that sub-optimal retirement saving is not a driving force and that unretirement is, instead, a lifestyle choice. Other studies of later life employment have also noted that finance is not as critical a factor in work/retirement decisions as sometimes assumed (Hirsch 2003; Sass 2016) - some individuals actively choose a lower retirement income and will adjust consumption rather than continuing or returning to work. Giandrea et al. (2010) and Kutlu-Koc (2014), however, analysing the American Health and Retirement Survey (HRS), do find evidence of the salience of financial factors and that compared with the security of a defined benefit pension, 
a defined contribution pension increases the incidence of unretirement as does lower wealth as measured by savings.

This study aims to contribute to the literature by means of an exploratory mixed methods and cross-cultural comparative approach, using a common analytical framework to investigate reverse retirement in three countries - England, the United States and Italy - to shed light on the influence of structural and cultural context and also to consider further the role of financial considerations. The study combines analysis of harmonised large-scale surveys to chart the incidence and determinants of reverse retirement with qualitative methods to present a more nuanced account of the motives and meanings of work, giving a voice to older, retired people.

Key research questions include: under what circumstances do individuals reverse retire (and how important is opportunity structure and cultural norms); and to what extent is reverse retirement a reluctant or constrained choice?

\section{Choice of Countries}

The three countries were chosen to reflect distinct economic and welfare regimes and cultural diversity. Public policies determine work opportunities, income and family responsibility constraints (reflecting provision of services); these different institutional settings might therefore lead to distinct opportunities within retirement and different plans for retirement lifestyles including orientations towards work. Two countries belonging to the same welfare regime (liberal) were selected to understand possible intra-regime differences, plus a country belonging to a different welfare regime in order to study inter-regime differences. Italy (a Mediterranean regime), was chosen to contrast with England and the United States given the notable difference in pension net replacement rates (much higher in Italy), potentially a key factor associated with decisions around returning to work.

Previous studies have demonstrated the value of cross-country analyses in highlighting the significance of economic incentive structures (Gruber \& Wise 1999), welfare regime type (Hofäcker 2010) and specific policy measures (Blossfeld et al. 2006, 2011; Ebbinghaus \& Hofäcker 2013; 
International Journal of Ageing and Later Life

Hofäcker et al. 2016) in explaining early retirement trends of the 80s and 90 s and their more recent reversal. Key determinants they identify are nation-specific labour market regulations, systems of taxation, employment activation policies, employment protection legislation, pension systems and education systems. Many of these institutional incentives and disincentives may also have a bearing on whether an individual chooses or is able to return to work after a period of retirement.

Italy represents a Mediterranean welfare regime where the role of the family is central (Ferrera 1996). Childcare and eldercare are predominantly delegated to the family. Formal care arrangements are less developed with implications for the range of options facing older people as they enter retirement, as retirees become a resource for caring roles.

England and the United States represent a liberal welfare model, characterised by de-familialisation with a broader role for private care (Bambra 2004), which enables individuals to participate in society (work, volunteering and other activities) and be independent from the family (Esping-Andersen 1990, 1999). However, there are a range of policy differences between these two countries.

In England, it is not possible to draw a state pension before SPa, but the tax benefit and pension systems permit individuals to work while drawing state and/or private pensions, providing a financial incentive to continue working beyond state pension age. In 2006, age discrimination legislation was introduced and in 2011 the default retirement age was abolished so older employees are no longer expected to retire once they reach SPa. Other measures introduced to promote flexibility and thereby support later life working include the 2014 Flexible Working Regulations which extend to all employees the statutory right to request flexible working such as reduced hours, flexitime or working from home (although employers can refuse requests on business grounds).

In the United States, a variety of pro-work incentives has impacted older Americans since the early 1980s (Cahill et al. 2016). In 1986, mandatory retirement was eliminated for the majority of American workers. The full retirement age (FRA) of the public pension system, known as social security, has been increasing, but early access to social security is permitted, currently from the age of 62 , with actuarial reductions. Other incentives include the delayed retirement credit (DRC) 
and elimination of the social security earnings test for individuals who work beyond the FRA.

The source and value of pensions also differ between the three countries. Seventy-two per cent of Italians' pension is from the first pillar of state provision compared with 50\% for the English and 38\% for Americans. In the United States and England, pensioners are more dependent on occupational and private pensions as sources of income. In both the United States and England, occupational pensions have shifted dramatically away from defined benefit plans to defined contribution plans leaving individuals more exposed to both investment risk and longevity risk later in life, creating an incentive to work longer to insure against both (Munnell 2014). It should also be noted that average net replacement rates (the value of pensions as a proportion of average earnings) stand at $81 \%$ in Italy, $42 \%$ in England and $47 \%$ in the United States (House of Commons 2015). Health insurance costs prior to Medicare eligibility are a further significant consideration for Americans.

The 'methods and analytic approach' Section 2 sets out the methodological approach and analytical methods. The 'Results' and 'Work orientation - cultural context' sections sets out findings from the two strands of analysis, while the 'Discussion' section discusses the findings and raises policy implications.

\section{Methods and Analytic Approach}

In exploring reverse retirement, secondary data analysis techniques are used to model patterns of employment behaviour and examine the factors associated with returning to work. In addition, to gain deeper insight into attitudes towards and experiences of retirement, analyses of depth interviews are also undertaken. This form of methodological triangulation (Denzin 2006) allows for a more rounded understanding of the influences which may lead individuals to return to work or refrain from making such a transition.

\section{Quantitative Methods}

The quantitative data analysis uses three data sources: the Survey of Health, Ageing and Retirement in Europe (SHARE); the English Longitudinal Study of 
International Journal of Ageing and Later Life

Ageing (ELSA) and the American Health and Retirement Survey (HRS). ${ }^{2}$ These longitudinal surveys collect information about health, employment, socio-economic characteristics and household circumstances among people aged $50+$ every 2 years. Compatibility between data sources has been aided by the Gateway to Global Aging Data platform (https://www.g2aging.org/) which provides syntax for variable harmonisation. ${ }^{3}$ The main outcome of interest is whether individuals return to work after a period of self-defined full retirement (dichotomized into 0 if the subject remains fully retired and 1 if she/he returns to work by the next interview wave); therefore, logistic regression is used. Returning to work was defined using a variable which asked whether respondents had been in paid employment in the previous month. This approach is likely to underestimate the incidence of reverse retirement somewhat as individuals may have returned to work briefly between waves but then retired again.

\section{Independent and Control Variables}

Informed by the study's key research questions, the models are designed to examine the significance of financial constraints as "push" factors. In addition to retirement income, household circumstances, including the number and ages of offspring, may drive reverse retirement on financial grounds. Parents make sacrifices for their children well into adulthood, often providing support with higher education costs or helping children to get on the housing ladder. Having younger children, more children or children still living at home may therefore make greater demands on parents' resources. In England in particular both housing and education costs have escalated dramatically in recent years potentially influencing parents' work-related choices. Economic factors modelled include

${ }^{2}$ For more information about these datasets, see the following websites: https:/ / g2aging.org/?section=survey\&surveyid=35 for the harmonised ELSA, https:// g2aging.org/?section=survey\&surveyid=60 for the harmonised SHARE and http:/ / www.rand.org/labor/aging/dataprod/hrs-data.html for the RAND HRS.

${ }^{3}$ In taking a harmonized approach, the study was unable to use some variables in the analysis that previous studies have indicated may be correlated with unretirement, in particular, the type of pension received (whether defined contribution or defined benefit). Occupational data were also incompatible as the three datasets used different classificatory approaches. 
retirement income decile; income squared (to test for a possible parabolic relation with the outcome variable); number of children; having at least one child aged under 30; having children living at home; and housing tenure (still paying a mortgage, own outright, rent, rent-free/other).

Previous studies have also highlighted the salience of "linked lives" (Elder et al. 2003), pointing towards the synchronisation of retirement transitions among couples and the extent to which life decisions are taken in the context of wider family considerations. In addition to the indicators relating to offspring above, variables include marital status (couple, separated/divorced/widowed, single) and whether a partner is working.

Other covariates which can influence opportunities to reengage with the labour market include key resources such as health, education and volunteering in addition to gender, age and caring responsibilities. Health status includes self-reported health (excellent/very good; good; fair/poor) and an indication of any work-limiting health problems. Caring responsibilities are included as a potential obstacle to work (a binary variable indicating whether any caring duties are performed at least once a week). Performing a volunteering role (at least once a month) is also added to the model - volunteering activities can expand social networks, thereby exposing individuals to other opportunities (Gonzales \& Nowel 2016) and, according to the role extension perspective (Hank \& Stuck 2008), people active in one area will also be active in another. Education level (below tertiary; tertiary/secondary school level; above tertiary) is also likely to influence opportunities to work.

\section{Qualitative Methods}

The study seeks to complement the modelling evidence by introducing the voices of retirees. Drawing on interviews, this element of the study fleshes out the quantitative analyses by providing greater depth of insight in relation to whether and why people may wish to return to work after a period of retirement, and the type of job they are seeking.

The qualitative strand of the study is based on semi-structured interviews (conducted by the authors and senior research colleagues) with 133 individuals in England, Italy and the United States. Fifty-five were conducted across England (mean age at recruitment 61) 40 in Central Italy (mean age at recruitment 60) and 38 in North West United States 
International Journal of Ageing and Later Life

(mean age at recruitment 62). All interviews in England and Italy were conducted face-to-face in participants' homes, in the United States a combination of face-to-face and telephone interviews were conducted; they were typically of 60-90 minutes duration. Over a period of 3 years people were interviewed up to three times - at baseline while they were still in employment and then on two further occasions once they had retired. The interviews were conducted between May and September in 2014, 2015 and 2016. ${ }^{4}$ Issues addressed included work experiences; the decision to retire; and retirement activity, satisfaction and orientations. People were identified by a recruitment agency in each country on the basis that they were working at least 30 hours a week and planning to retire in the next 12 months. Respondents were sampled purposively with reference to; income level, gender, partnership status and age as these were anticipated to affect opportunity structures and attitudes. All interviews were digitally recorded (with interviewee permission) and transcribed verbatim. Data management and analysis was conducted using NVivo and MAXQDA to thematically code interview transcriptions, using both deductive categories from the literature and inductive categories arising from the data itself to develop coding frames, which were then used independently by coders and checked (e.g. for missing/ overlapping categories and consistency in allocating data to particular categories).

Ethical issues were carefully considered at the outset of the study and, prior to data collection, approval from the host university's ethics committee was gained. All participants were given full information about the project and signed detailed consent forms prior to interview. All interview data have been anonymised and are held securely. To protect privacy, reference to participants below provides only basic information including age at wave 3, country of residence, gender and partnership status.

${ }^{4}$ By 2014, a range of pension policy reforms, discussed above, had been introduced in each country, including age discrimination legislation in Italy and England, abolition of compulsory retirement in England and disappearance of defined benefit occupational pensions in England and the United States. Increases to state pension age were also underway. 


\section{Results}

Reverse Retirement - Incidence and Determinants, Evidence from ELSA, HRS and SHARE

The incidence of returning to work in Italy, England and USA is shown in Figure 1. Reverse retirement is barely evident in Italy - the 2 year transition rate is just $2 \%$ among $50-70$ year olds. Transitions to retirement in Italy would therefore appear to effectively be a one way street. Reverse retirement is not common in England but 6\% made a return to employment from retirement. The two yearly incidence of reverse retirement is more common in the USA, at $10 \%$.

\section{Determinants of Reverse Retirement - Multivariate Regression}

\section{Analysis}

Table 1 sets out the results from logistic regression analyses. In comparing the three countries it is evident that very few factors achieve statistical significance in predicting reverse retirement in Italy, consistent with the rarity of this transition. The structural and cultural obstacles to reverse retirement in Italy are not challenged by financial need and the only significant predictors are age and gender. In all three countries, reverse

Figure 1. Incidence of "reverse-retirement" among 50-70 year olds by country

Source: HRS, ELSA and SHARE 2004-2012 pooled two yearly waves

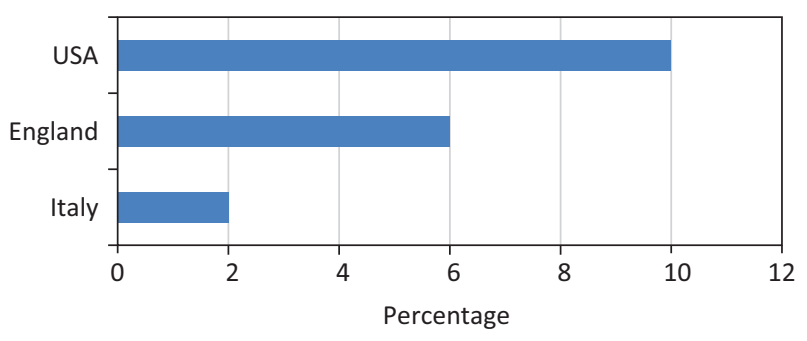


International Journal of Ageing and Later Life

Table 1. Multivariate logistic regression - determinants of reverse retirement

\begin{tabular}{|c|c|c|c|}
\hline \multirow{4}{*}{ Determinants } & England & Italy & $\begin{array}{c}\text { The United } \\
\text { States }\end{array}$ \\
\hline & $n=10,361$ & $n=2,852$ & $n=19,643$ \\
\hline & $R^{2}=0.1755$ & $R^{2}=0.1670$ & $R^{2}=0.1356$ \\
\hline & OR & OR & OR \\
\hline Female gender (ref. male) & $0.82^{* *}$ & $0.39^{* * *}$ & $0.74^{* * *}$ \\
\hline \multicolumn{4}{|l|}{ Age band (ref. 50-54) } \\
\hline $55-59$ & $0.66^{* * *}$ & $0.19^{* * *}$ & $0.66^{* * *}$ \\
\hline $60-64$ & $0.41^{* * *}$ & $0.11^{* * *}$ & $0.51^{* * *}$ \\
\hline $65-69$ & $0.33^{* * *}$ & $0.08^{* * *}$ & $0.39^{* * *}$ \\
\hline $70-74$ & $0.12^{* * *}$ & $0.05^{* * *}$ & $0.29 * * *$ \\
\hline $75+$ & $0.21^{* * *}$ & $0.01^{* * *}$ & $0.11^{* * *}$ \\
\hline Income decile & 1.04 & 0.72 & $1.22 * * *$ \\
\hline Income decile squared & 1 & 1.03 & $0.98^{* * *}$ \\
\hline \multicolumn{4}{|l|}{ Marital Status (ref. couple) } \\
\hline Separated/divorced/widowed & $0.62^{* * *}$ & 0.69 & $1.11^{* *}$ \\
\hline Never married & 0.69 & 4.42 & $0.74^{* *}$ \\
\hline \multicolumn{4}{|l|}{ Education level (ref. no education) } \\
\hline 1-13 school years & 1.12 & 0.88 & 1.1 \\
\hline $14+$ school years & 0.85 & 1.21 & $1.25^{* * *}$ \\
\hline \multicolumn{4}{|l|}{ Health status (ref. excellent/very good) } \\
\hline Good & 0.95 & 1.34 & $0.82^{* * *}$ \\
\hline Fair/poor & $0.56^{* * *}$ & 0.79 & $0.47^{* * *}$ \\
\hline Work-limiting health problems (ref. no) & $0.79^{* *}$ & 1.09 & $0.60 * * *$ \\
\hline \multicolumn{4}{|l|}{ Housing tenure (ref. paying a mortgage) } \\
\hline own outright & $0.58^{* * *}$ & 2.2 & 0.98 \\
\hline rent & $0.69^{*}$ & 2.56 & 0.94 \\
\hline rent-free/other & 1.13 & - & 0.79 \\
\hline Volunteer (ref. no) & $1.39 * * *$ & 1.48 & $1.41^{* * *}$ \\
\hline Carer (ref. no) & 1.12 & 1.39 & $0.90^{*}$ \\
\hline
\end{tabular}


Table 1. (Continued)

\begin{tabular}{lccc}
\hline & England & Italy & $\begin{array}{c}\text { The United } \\
\text { States }\end{array}$ \\
\cline { 2 - 4 } Determinants & $n=10,361$ & $n=2,852$ & $n=19,643$ \\
\cline { 2 - 4 } & $R^{2}=0.1755$ & $R^{2}=0.1670$ & $R^{2}=0.1356$ \\
\cline { 2 - 4 } & OR & OR & OR \\
\hline Partner employed & $2.13^{* * *}$ & - & $1.14^{* *}$ \\
No. of children & $1.09^{* *}$ & 1.06 & $1.02^{* *}$ \\
At least one child age $<30$ (ref. no) & $1.45^{* * *}$ & - & - \\
At least one child living at home (ref. no) & - & 0.88 & 1.09 \\
\hline
\end{tabular}
${ }^{* * *} p<0.01,{ }^{* *} p<0.05,{ }^{*} p<0.1$.

retirement is more common among men (particularly so in Italy) and the odds decrease progressively with age - consistent with previous studies.

In relation to financial factors, lower incomes do not increase the probability of returning to work in England but other economic factors do have an influence. Firstly, still having mortgage debt is associated with propensity to return to work. This determinant is not significant in Italy or the United States which may reflect the distinct British housing market. House prices in England have long been very high and continue to rise and it is therefore likely that mortgage debt is a greater burden. Secondly, having more children slightly increases the odds of returning to work, as does having a child under the age of 30 (plausibly due to the higher probability that they are still in education).

In the United States, income is a significant determinant, but the findings suggest an inverted $U$ shape, so it is the middle-income groups who exhibit the greatest odds of reverse retirement (consistent with evidence from Giandrea et al. 2010). Having more children also increases the probability of returning to work.

Non-financial factors are also significant. Not surprisingly, health status is critical - the worse the self-reported health the lower the likelihood of reverse retirement, with similar findings in relation to having a work-limiting condition. 
International Journal of Ageing and Later Life

Being active in a volunteering role enhances the probability of reverse retirement in all three countries (statistically significant in England and the United States). Being active in the community in a voluntary capacity may therefore present opportunities for paid employment and reflect individual aspirations for retired lives beyond the domestic sphere.

Consistent with previous studies which have found that couples often synchronise their retirements, having an employed partner increases the probability of reverse retirement in all three countries (although not statistically significant in Italy).

Years of schooling and caring responsibilities are not predictive of reverse retirement in Italy or England (although it should be noted that the caring variable does not capture intensity of caring). For the US sample, by contrast, caring significantly reduces the odds of returning to work while higher education levels increase the odds, achieving statistical significance among those who attended college or university.

In summary, reverse retirement is largely associated in the United States and England with a certain degree of socio-economic advantage; enhanced odds are related to being in younger age groups, in good health, with an employed partner and, in the United States, higher levels of education. There is also evidence of financial push factors increasing the odds of unretirement. In England, this includes having a mortgage to pay off, having a larger family and having children under the age of 30 . In the United States, higher income groups are less likely to unretire, with middle-income groups the most likely (low-income groups tend to have other health, education or employment history disadvantages which can act as a barrier to employment).

In Italy, the incidence of reverse retirement is so low that analyses, based on low sample sizes, struggle to detect significant effects. Therefore, findings only indicate that reverse retirement is associated with being a younger man.

\section{Lifestyle Orientations among Recent Retirees}

In the previous section, key socio-economic, demographic, family and health factors associated with reverse retirement were highlighted; these are representative of older populations but missing from the picture was a 
sense of how individuals feel about and experience retirement, what their priorities are at this time of life and how working fits into their new lifestyles. Drawing on interviews with individuals in Italy, the United States and England who have transitioned to retirement, deeper insights at the level of meaning are presented in relation to motivations to work and reasons for shunning opportunities to continue along a path of "productive" ageing despite, in some instances, apparent financial need.

Being eligible for a pension (state, occupational or private) were key triggers for retirement timing among the qualitative samples of retirees. Many were also keen to stop working while still in good health and able to enjoy their retirement years. For others, retirement was simply described as "normal." Job-related reasons for retirement were also prevalent such as stress, heteronomy, feeling worn out or commuting frustrations. Cited attractions of retirement in all three countries included spending more time with friends and family; more travel and leisure time; and freedom and time sovereignty. Summarising "orientations" towards retired life, several groups were identifiable across the three country samples (not mutually exclusive):

- Creatively oriented: A drive to be creative was common, with a broad range of interests including music, writing, photography, languages, theatre, painting, gardening and crafts. For many in this group, previous jobs, which they may well have enjoyed, did not provide a creative outlet, and retirement was therefore seen as providing an opportunity to explore new skills and interests or to return to passions which had been marginalised, in some cases decades ago.

- Family and home oriented: For many, working lives had squeezed the time available to spend with family and friends; retirement was seen as finally providing the opportunity to re-prioritise relationships and provide more support for family members.

- Leisure oriented: More frequent travel was one common aspiration as was the desire to pursue a wide range of hobbies, sporting or other physical activities (such as walking, golf, bowling and dancing) motivated by a desire to maintain or improve health once retired, as a useful means of occupying newly freed time and as a good source of social activity. 
International Journal of Ageing and Later Life

- Work oriented: This group wished to maintain the structure and/ or social engagement provided by employment and continue to use their skills. For some, this orientation also reflected perceived financial need whether for basics or for "extras."

Differences in the dominance/prevalence of each of these retirement orientations were evident when comparing retirees from each of the three countries, reflecting both cultural variation in relation to values and also distinct welfare regimes shaping the opportunity structure facing individuals at this stage of their lives.

Focussing on work orientation, there are clear differences among the three country samples, highlighted in Table 2. By wave 3 of the interviews, just one Italian had returned to work within 2 years of retiring (a further six expressed a desire to find some sort of a job but only one was actively searching, the remainder observed they had found no opportunities). Several Italians also expressed disappointment that their employer had denied them the opportunity to phase their retirement by means of a period of part-time work. At the other extreme, most of the American sample either continued to work despite stipulated intentions to retire, unretired soon after leaving a career job or expressed a desire to find work. The English sample fell between these two extremes - of

Table 2. Retirement trajectory and aspirations - outcomes by wave 3

\begin{tabular}{lccc}
\hline & Italy & England & $\begin{array}{c}\text { The United } \\
\text { States }\end{array}$ \\
\hline $\begin{array}{l}\text { Did not retire, continued working full } \\
\text { time }\end{array}$ & 0 & $6(13 \%)$ & $7(24 \%)$ \\
$\begin{array}{l}\text { Phased retirement (reduced hours with } \\
\text { same employer) }\end{array}$ & 0 & $2(4 \%)$ & $4(14 \%)$ \\
$\begin{array}{l}\text { Reverse retired } \\
\text { Retired but would like to re-enter the }\end{array}$ & $1(2 \%)$ & $11(23 \%)$ & $6(21 \%)$ \\
$\begin{array}{l}\text { labour market } \\
\text { Retired with no desire to return to work }\end{array}$ & $33(15 \%)$ & $5(11 \%)$ & $7(24 \%)$ \\
Total $N$ & 40 & $23(49 \%)$ & $5(17 \%)$ \\
\end{tabular}


47 interviewees at wave 1, 6 did not retire after all by wave 3 (usually citing financial reasons for their changed plans), while 2 continued working on a part-time basis and 11 reverse retired. Half the English sample (49\%) had retired by wave 3 with no wish or intention to return to work - a proportion which is somewhat under half that of the Italian sample (83\%) but three times higher than the American sample (17\%); a pattern broadly reflective of the survey-based evidence above.

Overall, the reverse retirees had much in common - they were all working locally; typically working far fewer hours, often on a flexible basis (e.g. a nurse who returned to an NHS nursing "bank" and worked two shifts per month); and most were in jobs with low entry barriers (e.g. low-skilled driving jobs, bar staff or in the retail sector); or they were exploiting skills they had developed over a life time, often on a self-employed/freelance basis (e.g. a heating engineer who became a self-employed plumber, an electrician now a self-employed odd job man and a retired reverend who now conducts occasional freelance funerals and weddings). Employment transitions and motivations for returning to work (which usually involve multiple reasons) are shown in Table 3 . Several of the reverse retirees are above state pension age, including a 73-year-old. Their average age, however, is 63 which is comparatively young (below state pension age), consistent with the quantitative evidence cited above which finds the risk of reverse retirement decreases with age.

Analysis of retirement narratives was conducted to better understand differences in work orientation and associated satisfactions with retired lifestyles.

Italians: family orientation and retirement as rest. Retirement was perceived by the Italians as a clearly demarcated phase of life with a strong expectation among both men and women that either a caring role or a strongly family- oriented lifestyle would be adopted. While some identified caring responsibilities as an obstacle to specific aspirations, on the whole, formal caring or a voluntary transition into a family support role was unquestioned and absorbed into life providing a sense of meaning, commitment, structure and a source of pleasurable relationships. One Italian woman typified this reorientation towards the home and family, and described taking on a "housewife" role in retirement: 
International Journal of Ageing and Later Life

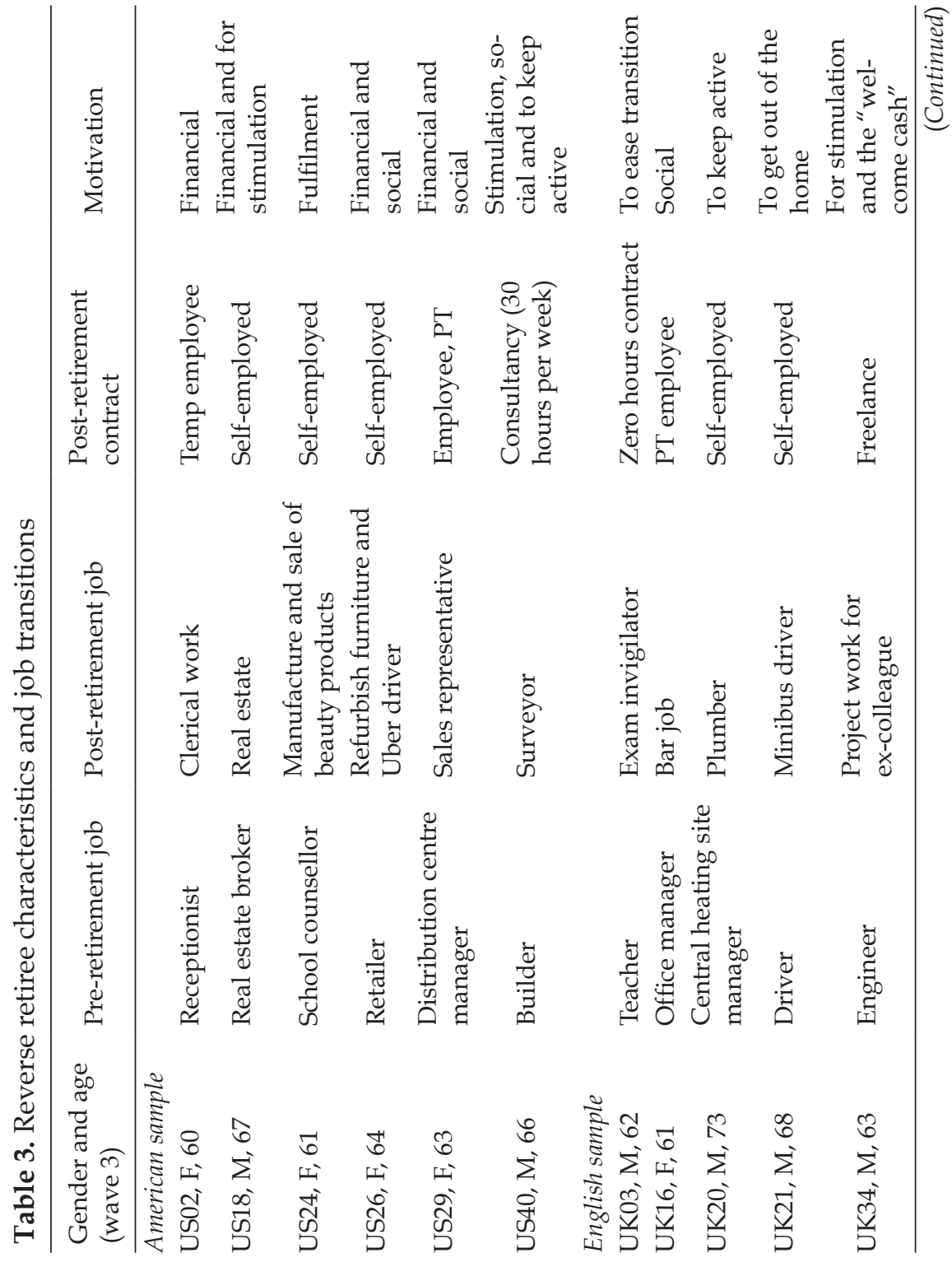


Reverse retirement - a mixed methods study

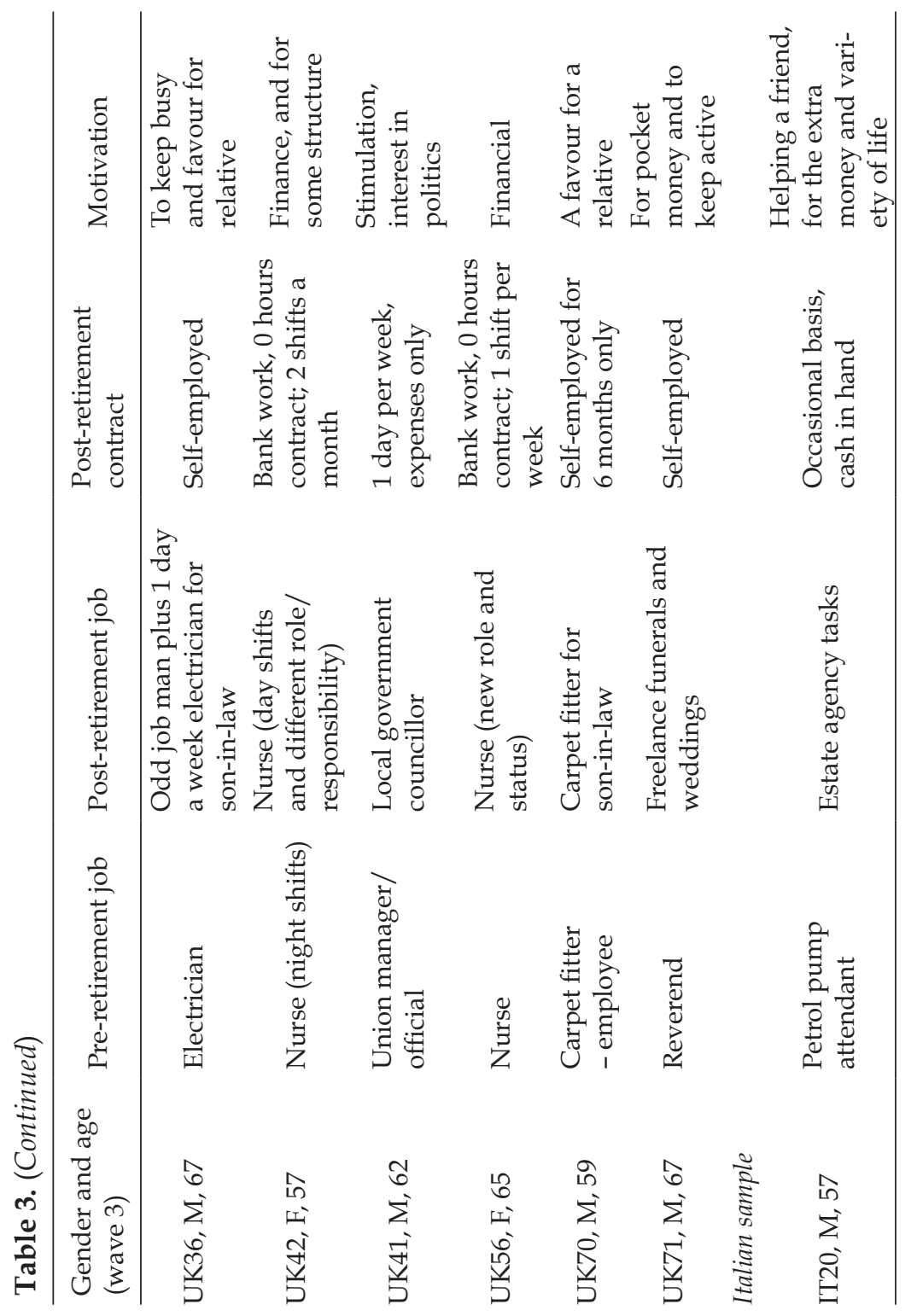


International Journal of Ageing and Later Life

\begin{abstract}
Now you try to do more for the family, to better look after the home, which, inevitably, had previously been neglected. So, now the most important thing for me is my family... I now have time to devote to myself and to my loved ones. (IT36, F, Age 60, lives with husband)
\end{abstract}

In comparing the three samples, of note was the extent to which Italians discussed the positive aspects of their retired life in very traditional terms of "relaxation," being "calm," using terms such as "serenity," "rest" and "tranquillity," expressing pleasure in living at a slower pace, napping and being more contemplative, with one retiree now never wearing a watch. This perspective could also be found among some of the English and American retirees, but "retirement as relaxation" was most dominant among the Italians who appeared culturally to regard the role of "pensioner" favourably, as a time to embrace a more sedate lifestyle as can be seen from the following quotes describing retirement:

Sweet doing nothing, I appreciate it. (IT07, F, 61, lives alone)

I do things more slowly, I'm not in a hurry anymore ... In general, my pace is slower, it is different now ... this sense of freedom is very beautiful. (IT17, F, 68, lives alone)

I have more time to reflect. An expression used by my father when he retired comes to mind: "you run, run, run, but for going where?" It's true. I enjoy little things... My pace of life is more relaxed, I'm doing a lot less than before. In short, it is important also to live with idleness. (IT21, F, 59, lives with husband and daughter)

The positive aspect of retirement is that I can be tranquil. (IT27, M, 61, lives with wife)

Over half the Italian sample valued their retired lives in these terms which was somewhat at odds with the principles of "active" and "productive" ageing, which emphasise the importance of "active" lives, "giving back" and are in tune with the "busy ethic" as expounded by Ekerdt (1986) who observed normative expectations that old age should be filled with activity. Exhortations for busy, active and productive retirements may therefore be culturally biased insofar as they appear consistent with the practices and expressed preferences of older Americans in particular but differ somewhat from descriptions of what represents a good life among the retired Italian sample. Although not all Italians were happy with retirement, some talked of monotony and being unhappy with 
various aspects of their lives, but very few saw opportunities to return to work as a solution to their dissatisfaction.

The Italians were also rather stoical in relation to money. While it was acknowledged that income may at times be tight, there was a sense that family, good health and freedom were more important than money. The Italian propensity to adapt to lower incomes rather than seek to earn more is captured in the following quote from an Italian woman:

I will not have enough money but I do not mind! If I have spent my money by the first day of the month and I have to wait until the 10th to receive my pension, what shall I do? I will check what we have available in the refrigerator... If I do not have fuel in the car I will not use it... But I will not start working again! (IT26, F, age 59, lives alone)

Americans: work orientation and retirement as a time for new challenges The Americans were more likely to see retirement as a new beginning, with opportunities for fresh challenges. They remained oriented towards work and were the least oriented towards leisure - reflective of the strong work ethic of Americans identified in previous studies (Nimrod et al. 2007, 2008). One American woman in her late 50s was asked whether she saw herself as retired now that she had left her teaching post and was drawing a generous pension, to which she responded:

No, I don't think I do. I think of it as the next step in my life, doing something different. (USID20, F, age 59, lives with husband)

The following interview excerpts similarly exemplify "retirement" as a time for change or new opportunities rather than as a one way exit from work:

Creative people don't retire, they may stop working but that's not retiring. (USID23, M, age 73 , lives alone)

I'm looking forward to doing something different. I have not yet decided what that might be. But I am looking forward to the challenge. (USID38, M, age 64, lives with wife)

I don't know whether you ever totally retire. I mean I don't plan to. I retired from my career for now. I'm going to be doing something else I'm just not sure what. (USID13, F, age 67 , lives alone) 
International Journal of Ageing and Later Life

Many were leaving career jobs and taking their pensions because they wanted to channel their energy differently, towards more meaningful work, better work-life balance or just for a change. Receipt of a pension provided people with the financial means to make changes and exercise choices based on shifting preferences. As found in other research, retirement among Americans was perceived as a "second act" in pursuit of new challenges rather than a "second childhood of boundless leisure" (Moen 2005: 203). This employment orientation is also consistent with evidence from Maestas (2010) who concluded that in the United States unretirement is largely anticipated in advance and not a result of financial shocks or poor planning.

Dissatisfaction with retirement was a further motivation for working, and one of the main sources of discontentment was the view that there were too few opportunities for social engagement and a lack of community that might facilitate casual or more regular social contact. This perception could also be found among a minority of the English and Italians, but was more prevalent among the Americans, many of whom talked of feeling lonely or isolated and the difficulty of making friends and finding people to "play with." Americans were particularly receptive to the idea of retirement groups (whether workshops, social groups, drop-in centres or similar) with two-thirds of the sample expressing enthusiasm for this kind of social support. Most Americans had sought and received financial advice prior to retiring but noted a vacuum in relation to non-financial support.

Given social engagement deficits, reverse retirement had a very beneficial transformative effect for one 65-year-old American man who, having retired, described his subsequent decrease in social activity and in activity more generally; he was not motivated by any passions or interests nor socially active and so spent his days reading and napping. During this time, he put on weight partly due to his diet which had deteriorated, especially in the evening with excessive snacking due to boredom. By wave 3 he had secured a new job:

I took it on because I was finding myself being bored and even less active and I didn't feel as much of a connection with anything because I have a fairly limited friend base, most of my adult life has been either home oriented or work oriented and having it be totally home oriented, I was finding that unsatisfactory. So I went back to work and this fulfils a number of criteria. (USID40, M, age 66, lives with wife) 
While evidence from some previous studies indicates that unretirement is not associated with financial need, the American sample of respondents did stand out as distinct in exhibiting a more general anxiety around money. In these instances, retirement income was often perceived as adequate with financial safety nets in the form of savings in place, but, having spent their lives conscious of the need to save and prepare, combined with uncertainty around how long resources would need to last, money was a constant source of worry. Financial concerns prompted a return to work in the following example of a woman with savings and a household pension income of around $\$ 7000$ per month (excluding earnings from a part-time job):

I do have financial reasons to want to continue ...like you can't count on your stock mar-
ket or even compound interest might be your friend but not with the interest rates we
have. I think that financial planning is so critical ... having saved everything they need
financially to last them the rest of their lives, I don't see how anybody. I mean I don't
even know if Donald Trump would have enough money, you know, at a certain point to
say "okay I've got all I need...." (USID28, F, age 64, lives with husband)

One 67-year-old American woman who was receiving \$2100 per month described her decision to return to work in order to continue earning almost as a moral imperative, despite being "tired of working" she observed:

You're supposed to earn all the money you can in your life while you can. (USID35, F, age 67 , lives alone)

English: leisure orientation and retirement as a patchwork of activities The British sample, in many respects, present a hybrid picture. There was a distinct subgroup who remained work oriented, but broadly speaking the English retirees could be described as predominantly leisure oriented.

Gardening was a particularly popular source of pleasure during retirement for the British - a creative activity that occupied long hours for both men and women, especially in the summer, providing a creative outlet and a key source of physical activity. Although some Americans and Italians were similarly enthusiastic gardeners, the lower proportions engaged in gardening activities reflect differences in housing in the three 
International Journal of Ageing and Later Life

countries. More of the English sample lived in homes with gardens - consistent with wider population level accommodation profiles. ${ }^{5}$

Compared with the Italians, the English were more resistant to fulltime homemaker roles; although family was a strong orientation for many of both the American and English samples, it differed somewhat in intensity. In relation to grandparenting, for example, some respondents felt they had done their bit, really enjoyed being grandparents but did not wish to be relied on as formal carers, as in the following example of a man who hoped to spend his retirement years free of constraints in order to travel:

\footnotetext{
I don't know why but when you're grandparents and you're at home and they know you're at home, "oh, by the way, could you just look after so and so for the day, or a couple of days"... but like I want to do things, I've had my children, it's their job now. I don't mind occasionally but [not] weeks at a time because of holidays. (EN17, Male, age 59, lives with wife)
}

Similarly in relation to eldercare, several of the English sample were caring but on a drop-in or remote support basis. As one English woman noted, as much as she loved her parents she was not going to sacrifice her life to perform a caring role:

My dad is eighty-seven and my mum is eighty-six [but] we are not going to become the main carers. They'll have to get carers in and we'll just keep an eye on them, because I do know people work all their lives then either have grandchildren to take to school and pick up and things like that and older parents as well.... We are determined that they can pay for their own care and we'll just prop them up. (EN43, F, age 60, lives with husband)

Among the work-oriented subgroup, a desire for considerable flexibility was evident. Where the prime attraction of retirement is time sovereignty and the ability to be spontaneous, reduced hours do not provide the degree of flexibility desired as part-time jobs still require a regular commitment. In the following example, it is evident that leisure is prioritised over work:

\footnotetext{
${ }^{5}$ A total of $53 \%$ of Italians live in apartments/flats compared with $34 \%$ across the United States and just 18\% in England (Eurostat 2014; Cox 2011).
} 
I don't really want to be tied down to anything too rigid because I do want to travel, it might be that I can find something that I could do one day a week for six months and then have six months off to then travel or do a couple of months at the beginning and then have a block off and then a couple of months .... (UK42: F, age 54, lives alone)

Zero hours contracts could meet the flexibility needs of these retirees. Although widely criticised as depriving people of employment rights, security and financial stability, these are not the job characteristics which older workers are necessarily searching for. One 58-year-old English man had found a highly flexible opportunity which he felt would work well and allow him the spontaneity he strives for:

\footnotetext{
...if there's no work then I don't go, simple as that, that's how I want it, very flexible. They have a bank of people so they're ring me up and say "Do you want to come up Monday help out?" and I'll say "Sorry, no, I'm going shopping with the wife" ... "Okay no worries" and they'll ring somebody else so it's quite easy going. (UK67, M, age 58, lives with wife)
}

These individuals differed somewhat from the Americans by seeing themselves primarily as retired but would appreciate and benefit from opportunities to work sporadically. The evidence calls into question the utility or accuracy of the term "reverse retirement." Most of the returners regard themselves as primarily retired and saw their jobs as supplemental - part and parcel of their retired lives. A more accurate description of the phenomenon might therefore be "working in retirement." The Americans were less likely to describe themselves as retired on re-entering the labour market.

\section{Work Orientation - Cultural Context}

Structural, cultural and historical reasons account for some of the differences between the three countries in terms of their values, perceptions of retirement and orientations to work at this stage of life. Employment opportunities are few among older Italians; in order to claim a pension, it is first necessary to withdraw from the labour force; there is a pervasive early retirement culture; and with high youth unemployment older workers feel it is their moral duty "to step aside" to the benefit of younger generations. In contrast, an emphasis on the right to work 
International Journal of Ageing and Later Life

has a strong history in the United States where abolition of compulsory retirement and age discrimination legislation were introduced in 1986. For England, such developments have a much more recent history - age discrimination legislation was introduced in 2009 with abolition of compulsory retirement in 2011. England is thereby in a process of transitioning away from retirement as a clearly defined status transition towards a notably more blurred demarcation, in other words it occupies a middle position between the Italian and American regimes.

A further characteristic of working lives that may have explanatory power in terms of cultural context is the strong American "work ethic" as measured by working hours (whether by choice or constraint). Table 4 highlights the differences between each country in terms of hours worked and vacation time with potential implications for how readily each group might transition and adapt to a traditional retirement of leisure. Americans stand out as having notably less leisure time throughout their working lives given longer weekly and annual hours and fewer vacation days. Americans work an extra half a day every week and 366 hours more per year than the British and the Italians. This equates to an additional 9 weeks of work every year (assuming a 40-hour week) - a discrepancy which is explained in part by longer working weeks but also by the fact that Americans take 2.7 weeks less vacation time than the British and 4.1 weeks less than the Italians. At the very least, these figures imply that, on average, Americans may be less prepared for a life of leisure than their European counterparts.

Table 4. Work and leisure - all ages

\begin{tabular}{lccc}
\hline & Italy & England & $\begin{array}{c}\text { The United } \\
\text { States }\end{array}$ \\
\hline Average weekly hours worked & 37.3 & 37.5 & 41.3 \\
Average annual hours of work & 1536 & 1530 & 1896 \\
Holidays and vacation weeks taken & 7.9 & 6.5 & 3.8 \\
\hline
\end{tabular}

Source: OECD, Society at a Glance 2009, special focus measuring leisure. 
Reverse retirement - a mixed methods study

\section{Discussion}

This article contributes to the small literature base which has examined the phenomenon of reverse retirement. The study set out to consider the circumstances under which individuals reverse retire; the significance of economic context, welfare regime, opportunity structure and cultural norms; and the extent to which reverse retirement reflects a reluctant or constrained choice.

Reverse retirement is not evident in Italy where retirement is still perceived as an earned right to be free from work, in part to make way for younger workers in a context of very high youth unemployment and supported by adequate public welfare provision with comparatively generous pensions. Italian narratives of retirement revolve strongly around traditional conceptions of winding down and playing a more dominant role in the lives of their families. This distinctive Italian attitude is consistent with findings from previous research which has highlighted that satisfaction among Italian retirees is more strongly associated with solid support networks and less with economic well-being (Ferring \& Wenger 2003; Polverini \& Lamura 2005).

In contrast, the normative ideal of retirement as an earned liberation from work would appear to have a weaker hold in the United States which is characterised by considerable diversity in the transition to retirement - including a widespread incidence of phased retirement, bridge jobs and semi-retirement (see Cahill et al. 2016), and a more ambiguous lay definition of retirement which is less bound to ideas of legitimised freedom from work. "Productive" ageing and remaining engaged in the labour market during "retirement" was found to be a common aspiration.

England seems to be moving towards the American retirement paradigm as ideally characterised by a patchwork of activities cutting across multiple life domains (family, work and civil society) but could still be characterised as having a foot in both camps.

Notions of "successful" or "adaptive" ageing as people enter and progress through their retirement years have been recognised as culturally contingent (Chung \& Dodder 1996; Dein \& Huline-Dickens 1997; Nimrod et al. 2008; Torres 2003), and findings from this study affirm the significance of context dependency. Using a cross-cultural and mixed methods approach, the study has highlighted considerable variety in retired 
International Journal of Ageing and Later Life

lifestyle preferences and complex decision-making in relation to working in retirement. Despite international policy convergence around the extended working life agenda, the meaning of retirement, lifestyle orientations and the role of work in retirement were still found to be quite distinct in Italy, the United States and England. A one-size-fits-all policy agenda, such as the normative goals of "active" or "productive" ageing, may be seen as a useful antidote to traditional conceptualisations of retirement as a time of disengagement and decline but risks an overly homogenised and prescriptive expectation of later life. Further research would be valuable, to include a wider range of countries (and regime types), to better inform Europe-wide policies (and beyond) designed to improve the experience of retirement as retired populations swell across the developed world. In addition to evaluations of the impact of different international labour market and taxation policies (reflecting distinct welfare regimes and political priorities), further research drawing on the voices of older people are also warranted to ensure that the needs, concerns and aspirations of older people are taken on board in policy formulation.

In relation to the economic push versus lifestyle choice debate, previous studies have largely concluded that financial factors do not typically play a significant role in reverse retirement decisions which reflect instead a voluntary retirement lifestyle choice. A more complex relationship between financial factors and the decision to return to work emerged from this study, arising from the methodological triangulation approach.

In Italy, cultural norms, a challenging economic environment and workplace policies combine to erect significant barriers to reverse retirement regardless of individual financial need. In the English context, although retirement income levels are not associated with unretirement, there are indications of wider financial considerations being relevant including outstanding debts and having children under the age of 30; depth interviews also surfaced financial motivations existing alongside other considerations (social in particular) and decisions were rarely monocausal. In the American context, the highest earners were least likely to unretire, while middle-income groups exhibited the highest propensity to return to work and depth interviews revealed that a strong financial anxiety often underscores decisions to return to work even among the more affluent. American retirees were also pushed back into work disappointed with opportunities for social engagement - consistent with 
earlier studies which have found disappointment with retirement to be a determinant of work returns (Lahey et al. 2006) and reflective of research by Patacchini and Engelhardt (2016), which found that the size and density of American's social network declined in retirement. However, while financial push factors and retirement disappointments were clearly identifiable, interviews revealed a more complex picture as employment was often described by the Americans in positive terms, as a new challenge or a new phase of life.

Combining the distinct methodologies enabled the study to highlight the interplay between cultural and structural factors. For example, in Italy there is little reverse retirement - explained in part by generous pensions and workplace polices, but interviews also surfaced a distinct culture which regards retirement as a deserved rest from work combined with opportunities to adopt new valued roles (carer, parent and grandparent). Similarly, comparing England and the United States, in both countries there is far more individual responsibility for pension adequacy; economic factors therefore represent a strong potential motivation to continue working. Yet, survey-based evidence reveals distinct patterns of work in the two countries - the qualitative evidence provided additional insights, indicating a dominant leisure orientation towards retirement in England, while a work orientation remains a strong cultural characteristic among the Americans.

The study also raised concerns around equality of opportunity later in life. On the whole, those with greatest financial need are also the most disadvantaged in terms of health, education or patchy employment histories (including women who have raised families) - these are key barriers to working. To the extent that unretirement is largely related to advantaged circumstances, capacity and opportunity constraints act to prevent reverse retirement from being a viable solution to poverty in later life.

The findings have a number of policy implications and raise questions around how working after retirement is conceptualised. Policies to enable and encourage reverse retirement in England in particular would be well advised to take on board evidence of a shift in preferences and orientation towards qualitatively more flexible arrangements. There is a clear demand for very flexible contracts, such as zero hours or short-term project work. While research has highlighted the importance in later life of a balance between discretionary time (leisure) and committed time 
International Journal of Ageing and Later Life

(work, volunteering and caring) for optimal well-being (Jun 2014), the preferences of many reverse retirees in this study strongly point towards an aversion to commitment in the sphere of paid or unpaid employment. Many of these retirees explicitly resisted the idea of paid work or volunteering, even on a part-time basis, on the grounds that it required a commitment they were unwilling to give.

Policies should not only address employment opportunities and flexibilities but should also focus on a broad range of support for those in retirement given that provision for the retired in many locales, across each of the three countries, seems weakly developed. Retirees highlighted too few opportunities for social engagement and community life and a lack of basic information advice and guidance that might smooth what is potentially one of the most challenging life transitions individuals make. A desire for workshops, drop-in centres, networks of support and other provisions was widely expressed and described succinctly by one 59-year-old Italian woman who spontaneously described what would have helped her transition: "There should be something for us pensioners ... they should give us a Guide for services for older or retired people. I would like something for those who are retiring, to help prepare for hobbies, or interests ... orientation courses, strategies to apply just before the transition to retirement. Yes, a guide to help us to psychologically and concretely prepare for retirement."

Finally, given the extent to which reverse retirement is associated with more advantaged circumstances, the policy shift towards extended working lives would seem to carry a risk of insufficient protection for some groups and an exacerbation of inequalities in older age. Significantly delaying state pension ages will have adverse consequences for those unable to continue working despite being most in need of opportunities to earn - implications for dignity in later life therefore emerge and policy solutions are needed, including the possibility of greater flexibility in accessing state pensions.

\section{Acknowledgements}

We are grateful for the financial support from the Lifelong Health and Wellbeing (LLHW) Cross-Council Programme (Grant ES/L002884/1). The LLHW funding partners for this award are the Economic and Social 
Research Council and the Medical Research Council. The authors also thank the research participants who kindly gave up their time and shared their experiences and thoughts.

\section{Corresponding Author}

Deborah Smeaton, Faculty of Social Sciences and Humanities, University of Westminster, 35 Marylebone Road, London NW1 5LS, UK. Email: D.Smeaton@psi.org.uk

\section{References}

Bambra, C. (2004). The worlds of welfare: illusory and gender blind? Social Policy and Society 3(3): 201-211.

Blossfeld, H.P., Buchholz, S. \& Hofäcker, D. (eds.). (2006). Globalization, Uncertainty and Late Careers in Society. London and New York: Routledge.

Blossfeld, H. P., Buchholz, S. \& Kurz, K. (eds.). (2011). Aging Populations, Globalization and the Labor Market: Comparing Late Working Life and Retirement in Modern Societies. Cheltenham, UK: Edward Elgar.

Cahill, K., Giandrea, M. \& Quinn, J. (2010). The Role of Re-Entry in the Retirement Process. U.S. Bureau of Labor Statistics Working Paper 439 (June). United States Department of Labour. Available on https://www.bls.gov/osmr/abstract/ec/ec100070.htm (Accessed May 2016).

Cahill, K., Giandrea, M. \& Quinn, J. (2016). To what extent is gradual retirement a product of financial necessity? Work Aging and Retirement $3(1): 25-54$.

Chartered Institute of Personnel and Development (CIPD). (2012). Managing A Healthy Ageing Workforce: A National Business Imperative. London: CIPD.

Chung, R. H. \& Dodder, R. A. (1996). Conceptualization of aging in a cross-national context. Mankind Quarterly 36(3/4): 285-295.

Cox, W. (2011). More Americans move to detached houses. New Geography, 11/01/2011. Available online: www.newgeography.com/ content/002506-more-americans-move-detached-houses (Accessed February, 2016). 
International Journal of Ageing and Later Life

Dein, S. \& Huline-Dickens, S. (1997). Cultural aspects of aging and psychopathology. Aging \& Mental Health 2(1): 12-120.

Denzin, N. (2006). Sociological Methods: A Sourcebook. Aldine Transaction.

Department for Work and Pensions (DWP). (2014a). Fuller Working Lives. London: The Stationery Office.

Department for Work and Pensions (DWP). (2014b). Fuller Working Lives Background Evidence. London: The Stationery Office.

Ebbinghaus, B. \& Hofaecker, D. (2013). Reversing early retirement in advanced welfare economies: A paradigm shift to overcome push and pull factors. Comparative Population Studies 38(4): 807-840.

Ebbinghaus, B. (2006). Reforming Early Retirement in Europe, Japan and the USA. Oxford: Oxford University Press.

Ekerdt, D. (1986). The busy ethic: Moral continuity between work and retirement. Gerontologist 26(3): 239-244.

Elder, G. H., Johnson, M. K. \& Crosnoe, R. (2003). The emergence and development of life course theory. In J. T. Mortimer \& M. J. Shanahan (eds.), Handbook of the Life Course (pp. 3-19). New York: Kluwer Academic/Plenum.

Esping-Andersen, G. (1990) The Three Worlds of Welfare Capitalism. Polity Press, Cambridge, UK.

Esping-Anderson (1999) Social Foundations of Post-industrial Economies. Oxford: OUP.

Eurofound. (2012). Income from Work after Retirement in the EU. Luxembourg: Publications Office of the European Union.

European Commission (EC). (2011). Social Agenda - The European Commission's Magazine on Employment and Social Affairs. Issue 26. Brussels. Cited in Timonen, V. (2016). Beyond Successful and Active Ageing. Bristol: Policy Press.

European Commission (EC). (2014). About the European Innovation Partnership on Active and Healthy Ageing. A Europe 2020 Initiative, Innovation Union. Available on http:/ / ec.europa.eu/research/innovation-union/ index_en.cfm?section=active-healthy-ageing\&pg=about (Accessed May 2016).

Eurostat (2014) Eurostat Statistics Explained. Online publication. Available on: http://ec.europa.eu/eurostat/statistics-explained/index. php?title=File:Distribution_of_population_by_dwelling_type,_2015_ (\%25_of_population)_YB17.png (Accessed January 2018). 
Ferring, D. \& Wenger, C. (2003). European Study of Adult Well-Being: (ESAW) Comparative Report on The European Model of Ageing Well. Available on http://cordis.europa.eu/project/rcn/60272_en.html (Accessed October 2014).

Ferrera, M. (1996). The 'southern' model of welfare in social Europe. Journal of European Social Policy 6(1): 17-36.

Foster, L. \& Walker, A. (2015). Active and successful aging: A European policy perspective. The Gerontologist 55(1): 83-90.

Gauthier, A. H. \& Smeeding, T. M. (2003). Time use at older ages: Cross national differences. Research on Aging 25(3): 247-274.

Giandrea, M. D., Cahill, K. E. \& Quinn, J. F. (2010). Bridge jobs: a comparison across cohorts. Research on Aging 31, 549-576.

Giarini, O. (2009). The four pillars, the financial crisis and demographics Challenges and opportunities. The Geneva Papers 34: 507-511.

Gonzales, E. \& Nowell, W. (2016). Social capital and unretirement: Exploring the bonding, bridging, and linking aspects of social relationships. Research on Aging 39(10): 1100-1117.

Gruber, J. \& Wise, D. (eds.). (1999). Social Security and Retirement around the World. Chicago, IL: University of Chicago Press.

Haider, S. \& Loughran, D. (2001). Elderly Labor Supply: Work or Play? Center for Retirement Research Working Paper No. 2001-04. Boston: Boston College.

Hank K, \& Stuck S. (2008) Volunteer work, informal help, and care among the 50+ in Europe: Further evidence for 'linked' productive activities at older ages. Social Science Research 38: 1280-1291.

Hasselhorn, H. M. \& Apt, W. (eds.). (2015). Understanding Employment Participation of Older Workers: Creating a Knowledge Base for Future Labour Market Challenges. Berlin: Federal Ministry of Labour and Social Affairs.

Hirsch, D. (2003). Crossroads After 50: Improving Choices in Work and Retirement. York: Joseph Rowntree Foundation.

Hofäcker, D. (2010). Older Workers in a Globalizing World. An International Comparison of Retirement and Late-Career Patterns in Western Industrialized Societies. Cheltenham, UK: Edward Elgar.

Hofäcker, D., Hess, M. \& König, S. (eds.). (2016). Delaying Retirement: Progress and Challenges of Active Ageing in Europe, the United States and Japan. Basingstoke: Palgrave Macmillan. 
International Journal of Ageing and Later Life

House of Commons. (2015). Pensions: International Comparisons. London: The Stationery Office.

Jun, J. (2014). Balance beyond Work Life: An Empirical Study of Older People's Time Use in the UK. Oxford, UK: University of Oxford.

Kanabar, R. (2015). Post-retirement labour supply in England. Journal of the Economics of Ageing 6: 123-132.

Kanabar, R. (2012). Unretirement in England: An empirical perspective. Discussion Papers in Economics No: 12/31.

Kidd, M.P., Metcalfe, R. \& Sloane, P.J. (2012). 'The determinants of hiring older workers in Britain revisited: An analysis using WERS 2004'. Applied Economics 44(4): 527-536.

Klevmarken, A. (2010). Who Works after 65? A Statistical Analysis. Stockholm: Statens Offentliga Utredningar (SOU), p. 85.

Kutlu-Koc, V. (2014). The Retirement-Consumption Puzzle and Unretirement. Netspar Discussion Paper 11. Tilburg: The Network for Studies on Pensions, Aging and Retirement.

Lahey, K. E., Kim, D., \& Newman, M. L. (2006). Full retirement? An examination of factors that influence the decision to return to work. Financial Services Review 15: 1-19.

Larsen, M. \& Pedersen, P. (2013) To work, to retire - Or both? Labor market activity after 60. IZA Journal of European Labor Studies 2: 21.

Macnicol, J. (2010) "Older men and work in the twenty-first century: What can the history of retirement tell us?". Journal of Social Policy 37(4):579-595.

Maestas, N. (2010). Back to work: Expectations and realisations of work after retirement. Journal of Human Resources 45(3): 718-748.

Moen, P. (2005). Beyond the career mystique: 'time in,' 'time out,' and 'second acts'. Sociological Forum 20(2): 189-208.

Munnell, A. (2014). The impact of aging baby boomers on labour force participation. Center for Retirement Research Briefing, February 2014, Number 14-4.

Nimrod, G., Janke, M. C. \& Kleiber, D. (2007). Expanding, reducing, concentrating and diffusing: Activity patterns of recent retirees in the United States. Leisure Sciences 31: 37-52.

Nimrod, G., Janke, M. C. \& Kleiber, D. A. (2008). Retirement, activity, and subjective well-being in Israel and the United States. World Leisure Journal 50(1): 18-32. 
ONS (2016). Overview of the UK population: February 2016. London: The Stationery Office

Organisation for Economic Co-operation and Development (OECD). (2015). Pension at a Glance 2015. Paris: OECD.

Parry, J. \& Taylor, R. F. (2007). Orientation, opportunity and autonomy: Why people work after state pension age in three areas of England. Ageing and Society 27(4): 579-598.

Patacchini, E. \& Engelhardt, G. (2016). Work, Retirement and Social Networks at Older Ages. Working Paper No. 2016-15. Boston, MA: Centre for Retirement Research.

Petterson, J. (2011). Instead of Bowling Alone? Unretirement of Old-Age Pensioners. Working Paper 2011:14. Uppsala: Department of Economics, Uppsala University.

Polverini, F. \& Lamura, G. (2005). Italy: Quality of life in old age. In A. Walker (ed.), Growing Older in Europe (pp. 55-82). Maidenhead: OUP.

Porcellato, L., Carmichael, F., Hulme, C., Ingham, B. \& Prashar, A. (2010). 'Giving older workers a voice: Constraints on the employment of older people in the North West of England'. Work Employment \& Society 24(1): 85-103.

Reynolds, F.A., Farrow, A. \& Blank, A. (2012) ‘Otherwise it would be nothing but cruises': Exploring the subjective benefits of working beyond 65. International Journal of Ageing and Later Life 7(1): 79-106.

Sass, S. (2016). How Do Non-Financial Factors Affect Retirement Decisions? Boston, MA: Centre for Retirement Research, Boston College, Research Briefing, Number 16-3.

Smeaton, D. (2015). Extending working life in the UK. IAGG-ER 8th Congress, Dublin, 23-26 April.

Smeaton, D. \& McKay, S. (2003). Working after State Pension Age: Quantitative Analysis. Research Report No. 182. London: DWP.

Smeaton, D. \& Vegeris, S. (2009). Older People Inside and Outside the Labour Market: A Review. Research report 22. Manchester: Equality and Human Rights Commission.

The Age and Employment Network (TAEN). (2013). Survey of Jobseekers Aged 50+. London: The Age and Employment Network. 
International Journal of Ageing and Later Life

Torres, S. (2003). A preliminary empirical test of a culturally-relevant theoretical framework for the study of successful aging. Journal of Cross-Cultural Gerontology 18(1): 79-100.

UK Commission for Employment and Skills (UKCES). (2014). The UK Commission's Employer Skills Survey 2014: UK Results. London: UK Commission for Employment and Skills. 